\title{
Predicting the outcome of plans: retrospect and prospects of the use of models in planning
}

\author{
G. Pozoukidou \\ University of Thessaly, \\ Department of Planning and Regional Development, Greece
}

\begin{abstract}
A planner who claims the quality and assets of his or her plans must be able to justify or even prove their anticipated outcomes. In the midst of the conflicting and sometimes contrasting views of how planning should be done, it seems that the use of models might be the most productive approach.

Information technology and urban models entered planning around the 1950s, in a very dynamic but also unilateral way. This in fact created two large groups of planning oriented professionals with regard to the use of models in planning. On the one hand there were the planners that argued that sophisticated analytical tools could provide the foundation for the new science of planning. On the other, there were the more imaginative, creative and wilful planners that viewed the rationalization and mathematical nature of analysis (maybe even the role of analysis itself), with much distrust.

Today there is still diversity in the way planners think about models and their role in plan-making. This probably results from the implicit assumption that models would somehow not aid but replace planners' control over the process of planning. If someone seeks the reason for this misperception he will come to the conclusion that it results from planners' limited understanding of what models as planning tools represent and that there has been little research for an appropriate role of information technology in planning. After 60 years of computers first entering planning profession, it won't be an overstatement to say that despite their unambiguous significance in planning and plan-making, there has been little or no use of them in professional planning practice.

This paper is an attempt to define or better redefine the role of models in planning and plan making. For that there is a review of information technology and its use in planning over the last fifty years followed by, a parallel exploration of the emerging philosophical needs and theories in planning discipline. The
\end{abstract}


purpose of this exploration is to help us establish a relationship between planning theory and information technology, which in turn will help us to set the theoretical background in thinking about the future generation of urban models.

Keywords: planning theory, urban models, land use modelling, planning support systems.

\section{Information technology and urban modelling: a retrospection}

Computers entered planning in 1950s, during a very optimistic era where planning was viewed as "an applied science," and for some computers offered "a revolutionary new potential that it may have an effect in redefining the process of planning" [10]. Use of computers entered planning through the concepts of geographic accessibility and gravity, and through metropolitan transportation studies that generated the now standard approach of trip generation, trip distribution, modal split, and network assignment [12].

Urban simulation models were the way for planners to begin using computer's ability to quickly, reliably, and accurately process large quantities of data. Ambitious federally funded programs promoted the development of integrated municipal information systems for monitoring the community development process and for improving the information base for market choice and public policy making. Nevertheless, the enthusiasm and belief that computer models and analytical techniques could be valuable, neutral tools of objective analysis was widely questioned in the 1970s. Until then, a great deal of time and money was spent developing very sophisticated models and information systems that were expected to transform academic research and planning practice [6].

In this context, the first generation of land use models emerged in North America during the 1950s, with the key assumption that traffic was a function of land use. The main reason these models emerged was the need for studying the interaction between the massive construction of highways (Federal Aid Highway Act in 1956 built 41,000 miles), and the affected land use. Basic economic theories were complemented by the application of physics to geographical problems (i.e. gravity and geographic accessibility concepts) and provided the intellectual foundation for the first era of models developed. Cities were growing fast and models seemed to be a rational way, or a tool, to handle the complexities that planners were confronting. Since planning was viewed as an "applied science," models were the tools that offered the greatest potential to study city systems. Linear econometric models, such as EMPIRIC, and nonlinear models, such as Lowry's, formed two different groups of models that attempted to replicate spatial interactions. There were also a group of models based not on simulating the existing system, but on optimizing it in accordance with various predetermined planning goals; however, few applicable models of that kind were developed.

Data requirements, computational problems, and a crude theoretical basis were probably the most serious constrains of the initial modeling efforts. Lee, in his article "Requiem for Large-scale models" identified the "seven sins" of largescale models and summarized the reasons why these models had no chance of 
being successful in planning practice $[8,14]$. In a later review of urban models, Michael Batty summarized the reasons why early modeling efforts were condemn to fail, but also stated that these early approaches left a legacy used to develop the next generation of models [3, 4].

Some of these early approaches are still highly significant in planning practice and are part of the new era of transportation and land use planning models in USA. Literature indicates that worldwide there were two serious practical efforts that started 40 years ago and continue to be operating in the field. These are DRAM and EMPAL developed by Putman at the University of Pennsylvania, which has been widely applied in North America and MEPLAN developed by Echenique at the University of Cambridge, which has been widely applied in Europe and South America [4].

Nevertheless, the optimism of the 1950s and 1960s was followed by the 1970s spectacular failure of the large-scale urban models and the early municipal information systems. Sophisticated analytical tools once assumed to provide the foundation for the new science of planning were found inappropriate for planning applications. Municipal information systems were found to be overly complex, poorly designed, too expensive, and rarely achieved the objectives for which they were designed [12]. This rough criticism on urban models reflected an attack not on models alone, but on the "rational" planning approach, which dominated planning theory and practice in the 1970s and assumed to undermine all attempts to use computers in planning.

However, this does not mean that planners abandoned the use of computers. Planning academia continued to develop sophisticated econometric input-output models. At the same time, academic research on large-scale urban models and systems analysis was taking place primarily as a way to understand urban systems and had little application in planning practice [15]. With the exception of computer tools used in transportation planning, most planning agencies had no access to - or perceived need for - the expensive, fragile, and hard to use mainframe computers of the 1970s era [12]. As a result, the demand for urban models declined.

Planners' interest for computer technology revived in late 1980s early 1990s. Tremendous advances in microcomputers had made computer technology available not only to academic researchers, but also to planning practitioners. The use of microcomputers was broad, but also shallow [13]. Many planners were using microcomputers for the general purposes of word processing, spreadsheet modeling, and data management to process documents and maintain administrative records. These tools were proven to be extremely useful for improving the content and appearance of office reports and office efficiency, but microcomputer potentialities to help in planning tasks were only just beginning to be realized. At the same time federal mandates raised the need for some largescale systematic assessment and predictions of the impacts of urban growth. Traditional large-scale urban models were once again considered for application, with Putman's DRAM/EMPAL and Echenique's MEPLAN at the "center" of such applications. 
Through the 1980s and 1990s there was a relative stagnation in urban modeling. There were though, two types of software that attracted substantial interest, the Geographical Information Systems (GIS) and Intelligent Knowledge Based Systems (IKBS). GIS provided extremely powerful capabilities for storing, analyzing, displaying, and defining relationships between geographically referenced information. Literature and practice demonstrated that GIS was an extremely useful tool for planning applications that would require routine processing of spatial data, such as land information retrieval and mapping, site selection, and land suitability analysis. However, when it came to modeling capabilities, GIS had a limited ability to serve planning needs. Consequently, GIS was used mainly to overlay, display, and analyze data from the modeling functions that had been performed outside the GIS environment or through special plug-ins.

It is also important to understand that the range of tools GIS and urban modeling software offered to planners crossed their range of tasks and, in some cases, required that users were experts in digital manipulation of data. In general, manipulation of data entails a considerable knowledge of statistical operations and requires professionals who are able to exploit this kind of usage. At the same time it would not be an exaggeration to say that there are few planners available and capable of doing such work. As a result, there might be excellent tools like GIS, but their capabilities are limited to the imagination and abilities of the user.

Despite the fact that GIS was probably the major tool through which a large amount of planning practitioners entered the digital world, GIS as a stand alone tool has not been capable of addressing traditional concerns of planning. Traditional concerns of planning incorporate notions and processes like this of plan analysis, plan prediction, plan prescription, and plan evaluation, or in other words "the sketch planning process," a concept that has been introduced and explored by Britton Harris [3, 8-10]. By the end of 1990s it was realized that a GIS alone could rarely meet the challenges posed by the diverse requirements of the planning profession. This realization led to an extensive effort to adapt the GIS tools and techniques in broader decision support systems that Harris in 1989 labelled Planning Support Systems (PSS).

During the same period, there was extensive research activity regarding the application of expert systems (ES) in planning, known also as Intelligent Knowledge Based Systems (IKBS). IKBS are computer programs that attempt to solve real world problems by modeling the reasoning process that an expert would use if faced with comparable problems. IKBS can be used for a wide range of tasks like help users formulate database queries, conduct database searches, perform site analysis and selection processes, and much more. Nevertheless, during that period very few IKBS were developed and actually used in planning practice [13]. The high development cost could not always be justified since the market for such tools were mainly public organizations, which usually have limited budgets. Also the available, at that time, technology did not permit the development of applications that were "attractive" and easy for planning practitioners to use. As a result, a limited number of such applications 
were developed and fewer were used in practice. Nowadays IKBS are reinventing themselves under the umbrella of software agents.

\section{Urban modeling in planning practice today}

Over the last five decades, expensive, fragile, remote and hard to use mainframe computers have been replaced by small, inexpensive, easy to use microcomputers that get faster, cheaper, more powerful, and easier to use every day. Dramatic improvements in display capabilities, screen resolution, processing speed, and data storage capacities have also been made. An entirely new kind of software has been developed that make possible the outgrowth of more flexible and user-friendly tools; however, the reality in planning practice remains the same. Available evidence suggests that computers on planners' desks are continuing to be used largely to word process documents, maintain budgets, and store data in order to improve management and increase office efficiency, and not to perform genuine planning tasks [12].

Planners' failure to use computers as tools in planning practice results in part from their limited understanding of what the tools stand for, the purpose they are designed for and in general their role in planning and plan making. This in turn leads to a lack of computer tools being designed to serve planning needs and help practitioners with the planning process in everyday practice.

\subsection{Evolution of urban models in the context of "Planning Theory" developments}

As mentioned earlier, one of the reasons that modeling tools are not widely used by planners is the fact that they (the modeling tools) are not able to serve the planning needs. "Planning needs" is not a constant concept, on the contrary, it is an ever evolving concept shaped each time by the prevalent theories in the planning field.

Historically, there has always been an imminent evolution of information technology and planning theory. Starting in the 1950s with the evolution of "planning as architecture" to an image of "planning as an applied science," it was the era where the first large-scale urban models entered the field of planning. These computer-based models expressed the ongoing optimism and faith in the efficacy of science and technology. This view was also empowered by the changes in the "design view" of planning to a "systems and rational process" view of planning that would eventually form the "rational" planning style. Later and with the emergence of the view of planning as a "political" process, "rationality" was rejected. The idea that there is one person (a.k.a. planner) who's specially qualified to make "better planning decisions" was rejected under the notion that "better" is a concept that contains judgmental values [20]. As a result, the serious questioning regarding the purposes, objectives, and functionality of urban models were fed by the conceptual changes in planning, and eventually led to the urban models' failure [12]. Planning theory evolved to embrace concepts of Paul's Davidoff advocacy view of planning in the late 
1960s and the view of the planner as the "facilitator" of planning decisions. This view of planning as a way to facilitate the differences amongst planning stakeholders shifted planning theory to a postmodernism approach, which is prevalent in the field today. The postmodernism approach rejects the epistemological basis of planning and the values from the normative theory of planning. In this context various kinds of "knowledge and experiences" become important next to the "scientific knowledge". A more negotiated, political, and facilitating planning becomes the prevalent planning discourse model that replaces the comprehensive, integrated, and coordinated planning.

Historically, there is not a definite relationship between the development of information tools and planning theory evolution. It is not yet clear if it is planning theory and philosophical needs that drives the development of planning tools and applications, or if it is the practical needs that drive the theoretical foundations. On that note, the following section is an attempt to help us create a vision that will set the theoretical groundwork for the development of planning tools and support systems. The vision begins by recognizing that the search for new information tools in planning ought to start with planning theories, concepts and philosophical questions that are prevalent in the field. Hence, the next section is a review of the most recent theoretical and conceptual evolutions in the planning field.

\subsection{The new planning context}

Over the last 15 years and with the shift to the postmodernism approach urban planning has been viewed as a communicative and deliberative practice. The main characteristic of this discourse model of planning is that it implies mediation between different interests. Individuals and groups who have an interest in planning matters are encouraged (with planners acting as facilitators) to "tell their own stories," which will help make planning judgments $[1,2]$. Forester, in his book the Deliberative Practitioner, claims that “...we are likely to learn far more in practice from stories than from scientific experiments" [7]. For instance, environmental changes, which urban planning tries to shape and regulate, typically affect different groups holding different and often conflicting values and interests. In this context, the central part of planners' work involves mediating between such groups to reach agreements about what is best to do in situations where land development or any other planning endeavour, affecting them is imminent or being contemplated. Furthermore, in a society where the process of planning is constantly changing it is the planner's job to ensure that all interests are given a fair or equal hearing. Accordingly, planning does not only involve designing physical spaces but also designing "deliberative spaces," or "argumentative spaces." Therefore, much of planning work involves talk of various kinds, with various groups, in order to reach agreements about what is best to do.

The ideas of "communicative planning" and "deliberative practice" that were first developed in the 1980s have evolved to todays "collective planning" or "collaborative planning" or "planning as reasoning together." In this context, information technology is seen as providing the information infrastructure and 
argumentative spaces that facilitate social interaction, interpersonal and interdisciplinary communication, and debate with the main purpose to achieve collective goals and deal with common concerns [7].

This new communicative/collaborative view of planning suggests that planning should not be viewed as a rational and abstract decision process with the main purpose to optimize overall system goals (i.e. environmental protection). Instead, it should be seen as an ongoing, interactive, and open process of interdisciplinary communication and collective design. This invokes collective and collaborative decision making and acting, where interpersonal and interdisciplinary knowledge is incorporated into the process. This view of planning creates the need for computer and planning support tools that would augment this approach. These tools should go beyond the supply of the knowledge and facts needed to support certain decisions, but also to provide intelligence [3]. The new generation of planning support systems should be able to facilitate collective design, social interaction, interpersonal communication, interdisciplinary cooperation or debate with the ultimate goal to achieve collective and interdisciplinary goals that would be converted to common goals.

Still, in the beginning of such endeavours it may sound very idealized, if not impossible, to design computer tools that would sustain the emerging theoretical concepts. However, it does suggest that the future planning support systems should be designed to support collective, collaborative, and interdisciplinary decision making and provide interactive and integrative procedures.

\section{The prospect: towards interdisciplinary, collaborative and democratic planning tools}

The nature of planning itself is multifaceted, which means that we need an array of computer tools from different disciplines to cover the various aspects of planning. A sole transportation, economic model or environmental model would be too limited to capture the dynamic nature of planning.

Furthermore, a new understanding about system dynamics should emerge based on the interaction of complex systems like this of cities. This new understanding should be incorporated into modeling interactions between the economic, environmental, social, and the transportation systems. Most common modelers will try to find boundaries and limit their domain in order to minimize interactions between the different domains and make the modeling job easier. Nevertheless, the reality is that the different domains do exist in the city and they do interact. This exact assumption created over the years a hard criticism on urban models and the believability of their results. Traditional urban models tend to be only economic or transportation models, or in the best case scenario, a land use and transportation. There are a lot of efforts where we have a connection between transportation and land use models, but still there is a deliberate ignorance about the rest of the components of an urban system [5]. To achieve a comprehensive understanding of how the city works as a system in a modeling environment requires the synthesis and integration of several conceptual frameworks. 
Along these lines modeling community realized that the multidimensional nature of cities required a multidisciplinary approach to modeling. Still there is a long way to go, starting with a revaluation of model purpose and function. A models' functionality should change and its theory's main purpose should be to teach users. This aspect of models is facilitated by bringing a number of models together under an integrated common framework where they can interact [3]. Therefore, a set of individual standing models that can interact with each other would replace the large integrated models that now dominate planning modeling efforts. This would enable us to address unstructured problems, realize unexpected aspects of a specific problem, and be able to communicate through stories with the representation of events, circumstances, and processes presented by a storyteller (e.g. planner, citizen, stakeholders). Under this notion, several academics have accepted the concept of Planning Support Systems (PSS) as an appropriate model or framework for combining a range of computer based methods and models into an integrated system that can support core-planning functions.

A PSS should include a full range of planners' traditional tools for urban and regional economic and demographic analysis, forecasting, environmental modeling, transportation planning, and predicting future development and land use patterns [16]. It must also include technologies such as expert systems [3], decision support aids, hypermedia systems [17-19] and group decision support systems. GIS is of course an important part of such systems, but a PSS cannot consist solely by a GIS. PSS should not be seen as a radically new form of technology that will replace the existing tools that planners use. Instead, it should be seen as a framework or a platform that integrates a full range of current (and future) information technologies useful in planning. A PSS also should not be viewed as a closed "black box" collection of computer models, but as a continuous and interactive process of analysis, design, and evaluation that constantly integrates new information $[3,4,9]$. Until now urban models have been designed as "black boxes," meaning that they were understandable only by few experts or by its designated users. Part of the PSS mentality is to redesign urban models as an attempt to open the black box not only to the few planners that are using them now, but also to other planning stakeholders. Under this notion, users will be able to understand the purpose of the models and the way they function; to interact with them, interpret and value their results.

Many of the analytical and display modules that can be parts of a PSS have already been developed and are available somewhere in a prototype form. The important and difficult task is integrating these modules into a coherent system that serve the needs of planning. Software tools that can deal with particular planning tasks should be developed utilizing data stored in standard formats, or generated by various analytical modules. Analytic and display models must then be combined into an integrated package and new linking/data exchange tools must be developed that can transfer data from one software to another [3]. Harris and Batty, after describing how a PSS should be designed, concluded that it should also be "....as far as possible self teaching" and "... and last but not 
least, the models and methods embodied in a PSS should be understandable to the user" [3].

This again emphasizes the significance of creating planning support systems that will be easy to use and understandable by the average planner. According to Klosterman, the ideal PSS is as easy to define as it will be difficult to implement [3]. The ideal PSS would be a fully integrated, flexible, and user friendly system that allows the user to select the desired analysis and forecasting tool(s) in order to determine the implication of the alternative policies, and to instantly view the results graphically in maps and charts with interactive video/sound displays.

However, creating such a PSS as Klosterman points out is quite optimistic given what we have now in our possession. It is not an undoable endeavour, but to be able to create such systems it would take a lot of small and tedious steps of advancements, both in modeling methods and user interfaces [3].

\subsection{The role of models in the new generation of support systems}

As mentioned before, planning problems are composed of different problem areas; specialized computer tools and suitable technologies support each one of these areas. Therefore, a "structure" that integrates a wide range of different technologies and theoretical frameworks is necessary.

At the same time, since each model covers a specific problem area of planning, then a combination of models to cover similar areas can also be insightful. Therefore, a multidisciplinary support system environment should encourage the use of more than one model for each problem area. Even using exactly the same inputs, these models would probably yield different results mostly because each one is based on different assumptions and encompasses a different simulation processes. Some seek equilibrium, others are dynamic, some include employment or transport of goods and some do not. The different results would raise questions, such as, how the differences should be explained and what models mean relative to each other. Using and array of different models within the same problem area could bring diverging, or converging results is potentially useful to the planning process. The downside of such an approach would be that diverging results could slow down the planning process, due to conflicting interests of the involved stakeholders. Hence one of the challenges is to create a computer modeling environment that will set a framework to bring together different models, a set of translations/translators that will enable models to talk to each other, and that will help us discover things about the models itself. The new generation of planning support tools should be treated as learning tools, and not only as predictive tools. An integrated system of models will allow us to explore various interactions between the models which can lead to discussions, arguments, and debates. This will enhance our knowledge about how urban systems work and motivate us to use technologies for improving decisions in real situation.

The multi-model approach that has been discussed here has one major advantage; it keeps in a large extend the integrity of each model. Each model is independent, but communicates with the rest of the models. That means that when designing the system we can make fewer compromises to the functionality 
and reliability of the individual models in order to adjust them for use in the system. In that way it allows us to examine the embedded narratives of each model and how they affect the rest of the models and the coherence of the overall system. It seems that within such systems the connotation of models is altered. Models are becoming a way to diagnose, identify, and learn about actions, reactions, and consequences. A support system that combines various models demonstrates to the user that each action has immediate (or not) consequences that the user has to confront. These types of support systems promote and improve the ability for dialogs, debates, discussions, and arguments and they not only reveal the functional complexity of our world, but also help us understand it.

Finally, we should not forget that the models and methods embodied in a PSS should be understandable to the user. After all, the purpose of these tools is to help planning practitioners perform their tasks in the real world.

\section{Conclusions}

In this paper there was a short review of the use of urban models and information technology in the planning field over the last 40 years. The purpose of the review was to emphasize the fact that we are on the verge of a transformation regarding the role of urban models and planning tools in the plan making process.

Planning theory shifted and philosophical concepts within the field changed. Thus models are not only used to stand for rationality and to justify decisions, but also as a communicative process. They are used as argumentative spaces, as a way to deal with the complexity of planning issues, which are full of incompatibilities, conflicts, and arguments over a universal principal vision and goals. Hence, we have the opportunity of giving urban models a new lease of life mandated by the requirements that are emerging from the new ways we define planning and plan making.

\section{References}

[1] Alexander, R., Doing the "impossible": Notes for a general theory of planning. Environment and Planning B: Planning and design, 25(4), pp. 667-680, 1998.

[2] Alexander, R., Rationality Revisited. Planning paradigms in a Post Modernist Perspective. Journal of Planning Education and Research, 19, pp. 242-256, 2000.

[3] Batty M., \& Yeh T., The Promise of Expert Systems for Urban Planning. Computer Environment and Urban Systems, 15, pp. 101-108, 1991.

[4] Brail, R., \& Klosterman, R., (eds). Planning Support Systems. Integrating geographical information systems models and visualization tools. ESRI Press, Redlands California, 2001.

[5] Costanza, R, \& Ruth, M., Using dynamic modeling to scope environmental problems and build consensus. Environmental Management, 22, pp. 183-195, 1998 
[6] Environmental Protection Agency, Projecting land-use change: a summary of models for assessing the effects of community growth and change on land use patterns. Technical Report-EPA-600-R-00-089, Cincinnati, Ohio: US Environmental Protection Agency, Office of Research and Development, 2000.

[7] Forester, J., The Deliberative Practitioner: Encouraging Participatory Planning Processes, MIT Press: Cambridge, MA-USA, 1999.

[8] Harris, B., The Real Issues Concerning Lee's "Requiem". Journal of American Planning Association, 60(1), pp. 657-663, 1994.

[9] Harris, B., Some thoughts on new styles of Planning. Environment and Planning B: Planning and Design, 21, pp. 393-398, 1994.

[10] Harris, B., Plan or Projection. An Examination of the use of Models in Planning. Journal of American Institute of Planners, 26, pp. 265-272, 1960.

[11] Kolsterman, R., An Introduction to the Literature on Large-Scale Urban Models. Journal of American Planning Association, 60(1), pp. 41-44, 1994.

[12] Kolsterman, R., International Support for computers in Planning, Editorial. Environment and Planning A, 26(7), pp. 387-391, 1994.

[13] Kolsterman, R., Evolving Views of Computer-Aided Planning. Journal of Planning Literature, 6(3), pp. 249-260, 1992.

[14] Lee, B., Requiem for Large-Scale Models. American Institute of Planners Journal, 3, pp. 163-177, 1973

[15] Openshaw, S., \& Openshaw C., Artificial Intelligence in Geography, John Wiley \& Sons, New York, 1997

[16] Putman, S., \& Chan, S., The Metropilus planning support system: urban models and GIS (Paper 5). Planning Support Systems. Integrating geographical information systems models and visualization tools, ed. Brail, R., \& Klosterman, R., ESRI Press, Redlands California, pp. 99-108, 2001.

[17] Shiffer, M.J., Spatial Multimedia for Planning Support (Paper 13). Integrating geographical information systems models and visualization tools, ed. Brail, R., \& Klosterman, R., ESRI Press, Redlands California, pp. 361-386, 2001.

[18] Shiffer, M.J., Managing Public Discourse: Towards the Augmentation of GIS, ed. Longley, et al. Geographical Information Systems, Management Issues and Applications, New York: Wiley, pp. 723-732, 1999.

[19] Shiffer, M.J., Towards a Collaborative Planning System, Environment and Planning B: Planning and Design, 19, pp. 709-722, 1992.

[20] Taylor, N., Anglo-American town planning Theory since 1945: three significant developments but no paradigm shifts. Planning Perspectives, 14, pp. 327-345, 1999. 